\title{
Rapid grounding line migration induced by internal ice stream variability
}

\section{Citation}

Robel, A. A., C. Schoof, and E. Tziperman. 2014. "Rapid Grounding Line Migration Induced by Internal Ice Stream Variability." Journal of Geophysical Research: Earth Surface 119 (11): 243047. https://doi.org/10.1002/2014jf003251.

\section{Permanent link}

http://nrs.harvard.edu/urn-3:HUL.InstRepos:41384977

\section{Terms of Use}

This article was downloaded from Harvard University's DASH repository, and is made available under the terms and conditions applicable to Other Posted Material, as set forth at http:// nrs.harvard.edu/urn-3:HUL.InstRepos:dash.current.terms-of-use\#LAA

\section{Share Your Story}

The Harvard community has made this article openly available.

Please share how this access benefits you. Submit a story. 
Journal of Geophysical Research: Earth Surface

\author{
RESEARCH ARTICLE \\ 10.1002/2014JF003251 \\ Key Points: \\ - Internal ice stream variability causes \\ significant grounding line migration \\ - Activation waves play an important \\ role in ice stream grounding \\ line migration \\ - Accurate simulation of ice \\ stream oscillations requires $1 \mathrm{~km}$ \\ model resolution
}

Supporting Information:

- Readme

- Text S1

- Animation S1

Correspondence to:

A. A. Robel,

robel@fas.harvard.edu

Citation:

Robel, A. A., C. Schoof, and E. Tziperman (2014), Rapid grounding line migration induced by internal ice stream variability, J. Geophys. Res. Earth Surf., 119, doi:10.1002/2014JF003251.

Received 18 JUN 2014 Accepted 19 SEP 2014

Accepted article online 23 SEP 2014

\section{Rapid grounding line migration induced by internal ice stream variability}

\author{
A. A. Robel ${ }^{1}$, C. Schoof ${ }^{2}$, and E. Tziperman ${ }^{1}$
}

${ }^{1}$ Department of Earth and Planetary Sciences, Harvard University, Cambridge, Massachusetts, USA, ${ }^{2}$ Department of Earth and Ocean Sciences, University of British Columbia, Vancouver, British Columbia, Canada

Abstract Observations indicate that the grounding line position of West Antarctica is sensitive to both forced and unforced ice stream variabilities. This study endeavors to characterize and understand unforced ice stream variability and associated grounding line migration. We use a flowline ice stream model with an undrained plastic bed, lateral shear stresses, and a stretched grid refined in the grounding zone. This model exhibits parameter space structure and hysteresis behavior similar to simpler ice stream models. Low prescribed temperature at the ice surface or weak geothermal heating produces thermal oscillations between active and stagnant phases. As in previous spatially resolved ice flow models, thermal activation propagates as an "activation wave." This model's fine resolution of the grounding zone allows for accurate simulations of transient, unforced grounding line migration. Upstream of the grounding zone, horizontal grid spacing of $1 \mathrm{~km}$ is required to accurately resolve activation waves. Activation waves induce the grounding line to migrate over $100 \mathrm{~km}$ at a rate that can exceed $1 \mathrm{~km} / \mathrm{yr}$. This is followed during the active phase by retreat, which then continues for the duration of the stagnant phase. Grounding line retreat is the result of a negative mass balance near the grounding line but is not necessarily associated with negative mass balance for the entire ice stream in our simulations of internal variability. The novel approach and experiments described in this study show that there can be large excursions in grounding line position in the absence of either external forcing or retrograde slopes.

\section{Introduction}

Ice streams are regions of fast ice flow that account for over $90 \%$ of the mass flux from the interior of the Antarctic Ice Sheet into ice shelves and other margins [Bamber et al., 2000]. Ice stream flow exhibits variability at a range of spatial and temporal scales, with stagnation and reactivation of fast flow on centennial to millennial time scales playing an important role in the present mass balance of the West Antarctic Ice Sheet. Radar measurements of buried crevasses indicate that Kamb Ice Stream stagnated 150 years ago [Retzlaff and Bentley, 1993], resulting in the currently positive mass balance of the Siple Coast [Joughin and Tulaczyk, 2002]. Satellite radar interferometry and ground-based GPS studies have also recorded ongoing deceleration of Whillans Ice Stream [Hulbe and Whillans, 1997; Joughin et al., 2005]. Simultaneously, satellite observations [Rignot et al., 2008] indicate that the acceleration of Pine Island Glacier has resulted in a large, negative mass balance in the Amundsen Sea sector. Fahnestock et al. [2000] found that recent centennial-scale variability in several Siple Coast ice streams is recorded in visible satellite imagery of streaklines on the Ross Ice Shelf. Subsequent studies from Hulbe and Fahnestock [2007] and Catania et al. [2012] used an integrated data-model approach to show that low-frequency ice stream variability over the past millennium was accompanied by significant excursions in grounding line position.

In addition to the integrated data-model approaches, observations of submarine, englacial, and subglacial features are also important indicators of the significant difference between past and present grounding line positions. A number of studies (reviewed in Livingstone et al. [2012]) have used the presence of grounding zone wedges and moraines on the Antarctic continental shelf to infer grounding line positions during the last deglacial retreat of paleo-ice streams. The size of these bedforms implies occasional halting of ice stream grounding lines lasting 100-10,000 years [Anandakrishnan et al., 2007; Dowdeswell et al., 2008; Graham et al., 2010]. Additionally, radar and seismic observations from underneath modern Siple Coast ice streams find deformed ice-internal stratigraphy from relict grounding lines [Catania et al., 2005] and multiple stacked sediment packages [Luthra et al., 2013] that are 80-100 km from the modern grounding line location. 
Fast ice stream flow in West Antarctica is caused by the deformation of subglacial till weakened by meltwater produced at the bed [Alley et al., 1986; Blankenship et al., 1986; Engelhardt et al., 1990]. Many mechanisms (reviewed in Bennett [2003]) have been proposed to explain the low-frequency variability in ice stream flow, including hydraulic surging, erosion of subglacial till, variations in ice shelf buttressing, and interactions with other ice streams. A number of studies have also explored how changes in subglacial till properties and meltwater production may explain centennial to millennial-scale ice stream variability and stable spatial oscillations in ice velocity [Kyrke-Smith et al., 2013]. Attempts to understand these mechanisms have ranged in complexity from simple models [MacAyeal, 1993; Tulaczyk et al., 2000b; Robel et al., 2013] to flowline models [Bougamont et al., 2003a, 2003b; van der Wel et al., 2013], to high-order ice flow models [Bougamont et al., 2011]. A common feature of these models is the thermal regulation of meltwater production at the bed, which is capable of producing oscillatory ice stream flow. Such a mechanism is broadly similar to early models of mountain glacier surge behavior [Robin, 1955; Clarke, 1976].

A few studies have explored the relationship between ice stream variability and grounding line position. Thomas et al. [1988] offered a conceptual interpretation of ongoing changes in the Siple Coast grounding line that invoked ice stream thermal oscillations. Perhaps confirming such an interpretation, Hulbe and Fahnestock [2004, 2007] simulated large-scale migration of the Siple Coast grounding line in response to prescribed ice stream variability. They separately posited that such variability could be caused by oscillations in the basal thermal regime. Hindmarsh and Le Meur [2001] showed that noise-induced drift due to internal ice stream variability could cause grounding line retreat, with an external temperature forcing. However, only recently has the representation of the grounding line in models achieved the level of sophistication necessary to accurately model transient grounding line flux and position. Schoof [2007b] showed that high resolution is needed near the grounding line in order to accurately capture the mechanical transition zone from ice sheet to ice shelf flow. Fried et al. [2014] used a model with refinement near the grounding line to show how the Siple Coast grounding line would respond to prescribed variations in bed traction simulating ice stream variability. Such an approach has also been used in transient simulations of ice stream response to forcing [Goldberg et al., 2009; Pollard and DeConto, 2009; Nick et al., 2009; Katz and Worster, 2010; Jamieson et al., 2012; Cornford et al., 2013; Favier et al., 2014].

To determine the significance of forced ice stream variability, it is imperative to first characterize natural modes of unforced ice stream variability and their mechanism. As such, the focus of this study is unforced ice stream variability at centennial to millennial time scales, which has a significant influence on ice sheet mass balance. In section 2, we describe a novel implementation of an ice stream flowline model which allows for accurate calculation of transient grounding line migration and activation wave propagation. In section 3 , we show that this flowline model is similar to the box model of Robel et al. [2013] in parameter space structure and hysteretic transition between steady-streaming and oscillatory behavior. As in previous studies [Oerlemans, 1982; Fowler, 1987; MacAyeal, 1993; Payne, 1995], we demonstrate (in section 3.1) that internal variability arises due to thermal feedbacks in meltwater production at the bed. We find (in section 3.2) that in a longitudinally resolved model, these oscillations produce activation waves that propagate via a coupling of longitudinal stress and frictional heat production. In our model, activations waves are smoothed by the inclusion of longitudinal stresses and meltwater storage in till, though they still require fine upstream grid resolution to be accurately resolved (section 3.3). Section 4 shows how activation waves cause mass to be transported to the grounding line, producing rapid grounding line migration during the active phase. This key result shows that significant grounding line variability can occur in the absence of retrograde slopes or external forcing. Migrations of the grounding line are solely due to mass imbalances near the grounding line, which may not be representative of the overall ice stream mass balance in our simulations of internal variability. Section 5 explores the parametric sensitivity of variability in the ice stream flowline model. We conclude (sections 6-7) that it is important to consider the potential significance of internal ice stream variability when interpreting geological evidence of past grounding line positions and the potential for future instabilities in grounding line position.

\section{Model Description}

This study uses a depth-integrated shallow ice stream model, incorporating integrated lateral shear stress, meltwater production, an undrained Coulomb plastic till layer, and dynamic ice temperature. This model permits the exploration of ice stream behavior arising from the coupling of ice stream thermodynamics to undrained till hydrology. Section 2.1 describes the ice stream force balance and an approach for 
calculating alongstream velocity, followed by ice thickness and grounding line position in section 2.2 , ice temperature in section 2.3, till properties and meltwater production in section 2.4 , cold-temperate transitions in section 2.5, and model numerics, including the stretched coordinate system in section 2.6. The assumptions made herein are appropriate for so-called "pure ice streams" in West Antarctica and the Laurentide Ice Sheet on sufficiently long time scales that surface meltwater production is negligible. An extensive derivation and discussion of the flowline model can be found in the supporting information.

\subsection{Ice Stream Velocity}

The horizontal force balance along a central ice stream flowline is

$$
\frac{\partial}{\partial x}\left(2 h \bar{A}^{-\frac{1}{n}}\left|\frac{\partial u_{b}}{\partial x}\right|^{\frac{1}{n}-1} \frac{\partial u_{b}}{\partial x}\right)=\tau_{d}(x, t)+\tau_{b}(x, t)+G_{s} h\left|u_{b}\right|^{\frac{1}{n}-1} u_{b}
$$

where $u_{b}(x, t)=u(z=b ; x, t)$ is the basal ice velocity $\left(b=b(x)\right.$ is bed elevation) and $\tau_{d}=\rho_{i} g h \frac{\partial h}{\partial x}$ is the driving stress. The term on the left-hand side is the longitudinal stress, and the three terms on the right-hand side are (respectively) the driving stress, basal shear stress, and cross-stream integrated lateral shear stress (as in Dupont and Alley [2005]). The basal velocity $u_{b}$ is assumed to result from till deformation. $\bar{A}$ is the vertically integrated Nye-Glen Law coefficient which is a function of ice temperature, $n$ is the Nye-Glen Law exponent, and $G_{s} \propto W^{-1}$ is a parameter capturing the importance of lateral shear stress where $W$ is the ice stream half-width.

Longitudinal stress is assumed to balance water pressure at the grounding line [Shumskiy and Krass, 1976]

$$
\left[2 \bar{A}^{-\frac{1}{n}} h\left|\frac{\partial u_{b}}{\partial x}\right|^{\frac{1}{n}-1} \frac{\partial u_{b}}{\partial x}\right]_{x=x_{g}}=\frac{1}{2} \rho_{i} g\left(1-\frac{\rho_{i}}{\rho_{w}}\right)(1-f) h\left(x_{g}\right)^{2} .
$$

Where $f$ is a parameterization of back stress due to ice shelf buttressing [Dupont and Alley, 2005]. When $f=0$ (as it is in the baseline simulation), the ice stream is unbuttressed, and when $f=1$, the ice stream is fully buttressed.

The upstream boundary is defined to be the ice divide, and correspondingly, velocity is set to zero there: $u_{b}(x=0)=0$. Without any upstream ice sheet inflow, the ice stream is self-contained.

Vertical shear of horizontal velocity is added separately to the basal velocity assuming that it arises independently due to driving stress

$$
u(z)=u_{b}+\frac{2 \bar{A}}{n+1} \tau_{d}^{n} h\left[1-\left(1-\frac{z-b}{h}\right)^{n+1}\right] .
$$

Enforcement of $x-z$ mass continuity allows for the calculation of vertical velocity, by integrating upwards from the bed at constant $x=x_{0}$

$$
w(x, z, t)=-\left.\int_{b}^{b+h} \frac{\partial u}{\partial x}\right|_{x=x_{0}} d z
$$

subject to the condition $w+u \frac{\partial b}{\partial x}=0$ at $z=b$. Elsewhere, we also refer to the column-averaged horizontal velocity $\bar{u}(x, t)=\frac{1}{h} \int_{b}^{b+h} u(x, z, t) d z$.

\subsection{Ice Thickness and Grounding Line Position}

Ice thickness evolves by simple advection

$$
\frac{\partial h}{\partial t}+\frac{\partial}{\partial x}(\bar{u} h)=a_{c}-m
$$

with a constant source of accumulation, $a_{c}$, everywhere along the flowline. $m$, the basal melt rate, is generally neglected in this equation as it is 1-2 orders of magnitude smaller than accumulation rate in a grounded ice stream.

By definition, ice begins to float at the grounding line,

$$
\rho_{i} h\left(x_{g}\right)=\rho_{w} b\left(x_{g}\right),
$$

where $\rho_{i}$ is the density of glacial ice and $\rho_{w}$ is the density of seawater. 


\subsection{Ice Temperature}

Calculating ice temperature along the flowline is necessary for reliable determination of the basal heat budget. We model temperature with the advection-diffusion equation in the $x-z$ plane

$$
\frac{\partial T}{\partial t}+\frac{\partial}{\partial x}(u T)+\frac{\partial}{\partial z}(w T)=\kappa\left(\frac{\partial T}{\partial x^{2}}+\frac{\partial T}{\partial z^{2}}\right)
$$

where $\kappa$ is the thermal diffusivity of glacial ice.

At the ice surface, the temperature is equal to a prescribed atmospheric temperature: $T(z=b+h)=T_{s}$. At the bed, ice temperature is assumed to be at the pressure melting point: $T(z=b)=T_{M P}$ (see discussion of this assumption in section 2.5). There is no heat flux through the ice divide and grounding line: $\left.\frac{\partial T}{\partial x}\right|_{x=0, x_{g}}=0$.

\subsection{Till Properties}

Subglacial till properties evolve in a manner similar to Robel et al. [2013], which is a modified form of the undrained plastic bed model of Tulaczyk et al. [2000b]. The basal melt rate, $m$, is calculated from the basal heat budget

$$
m=\frac{1}{\rho_{i} L_{f}}\left(G+\tau_{b} u_{b}+\left.k_{i} \frac{\partial T}{\partial z}\right|_{z=b}\right)
$$

where, on the right-hand side, the first term is the geothermal heat flux, the second term is the frictional heat flux, and the third term is the vertical conductive heat flux at the bed. $k_{i}$ is the thermal conductivity of glacial ice and $L_{f}$ is the latent heat of fusion.

Till void ratio, $e=\frac{z_{w}}{Z_{s}}$, is a ratio of the thickness of void spaces in the till column $\left(Z_{w}\right)$ to unfrozen solid till thickness without void spaces $\left(Z_{s}\right)$. Assuming that meltwater always fills the void spaces in the till column, the till water content can then be defined as $Z_{w}=e Z_{s}$. e and $Z_{s}$ then vary as a function of the ice stream state.

Void ratio is assumed to evolve freely when either above or increasing from a specified lower consolidation threshold, $e_{c}$

$$
Z_{s} \frac{\partial e}{\partial t}=\left\{\begin{array}{l}
m \text { if } e>e_{c} \\
m \text { if } e=e_{c} \text { and } Z_{s}=Z_{0} \text { and } m>0 \\
0 \text { otherwise }
\end{array}\right.
$$

where $Z_{0}$ is the maximum available till thickness.

To prevent the development of unphysical void ratios, many ice stream models which implement a version of the undrained plastic bed model [e.g., Bougamont et al., 2011; van der Wel et al., 2013] set a minimum attainable void ratio (equivalent to $e_{c}$ here). In reality, till freezes on at this void ratio threshold. When void ratio reaches its lower threshold in models which do not include till freeze-on, additional basal cooling $(m<0)$ has no effect on the till state. Thus, energy is not conserved and future basal heating $(m>0)$ will immediately begin to increase void ratio from the prescribed minimum. In simulations where void ratios reach this minimum and then begin to increase again, the duration of ice stream stagnation will be significantly different, as till does not need to thaw. Our model includes the process of till freeze-on, ensuring that the duration of ice stream stagnation is accurately simulated and energy is conserved.

When the void ratio reaches $e_{c}$ from above, till begins freezing on as a frozen fringe [Rempel, 2008]. $Z_{s}$, the current thickness of unfrozen till without void space, can be modeled accordingly

$$
e \frac{\partial Z_{s}}{\partial t}=\left\{\begin{array}{l}
m \text { if } 0<Z_{s}<Z_{0} \\
m \text { if } e=e_{c} \text { and } Z_{s}=Z_{0} \text { and } m<0 \\
0 \text { otherwise }
\end{array}\right.
$$

Equations (9) and (10) cover all possible till states, with the exception of $Z_{s}=0$, which is discussed in section 2.5 . 
The basal shear stress is calculated from the basal velocity and void ratio assuming that the till behaves as a Coulomb plastic material

$$
\tau_{b}=\tau_{c} \frac{u_{b}}{\sqrt{u_{b}^{2}+\epsilon_{u}^{2}}},
$$

where $\epsilon_{u}$ is the velocity scale over which till transitions from a quasi-linear to Coulomb friction law. The critical failure strength of the till follows the empirical form of Tulaczyk et al. [2000a]

$$
\tau_{c}=\tau_{0} \exp \left[-b\left(e-e_{c}\right)\right]
$$

where $\tau_{0}$ and $b$ are empirical parameters.

\subsection{Cold-Temperate Transition}

For sufficiently strong basal freezing, the entire till layer undergoes freeze-on $\left(Z_{s}=0\right)$. Basal ice then cools below the melting point in the same fashion as in the lumped model of Robel et al. [2013] and in inter-ice stream ridges. However, the migration of a cold-temperate transition at the bed in a longitudinally resolved model requires the simulation of physical processes not included in a typical thin-film, semi-depth-integrated model [Schoof, 2012]. As such, we omit these physics, with the proviso that our model is only valid for simulations in which the till layer never completely freezes through.

\subsection{Stretched Coordinates and Model Numerics}

The ice surface and grounding line constitute free boundaries of the grounded ice stream. It is thus advantageous to formulate the numerical solution in a stretched coordinate space

$$
\begin{aligned}
& \sigma=\frac{x}{x_{g}} \\
& \eta=\frac{z-b}{h}
\end{aligned}
$$

where $x_{g}=x_{g}(t)$ is the grounding line position, $h=h(x, t)$ is the ice thickness, and $b=b(x)$ is the bed elevation (in a similar fashion to Katz and Worster [2010]). In this system, the grounding line is always at $\sigma=1$ and the ice surface is always at $\eta=1$. This approach prevents the strong grid size dependence in fixed grid solutions [Vieli and Payne, 2005] and allows grid refinement near the grounding line for accurate calculation of transient grounding line migration. This numerical approach is similar to moving grid models without coupling to an ice shelf (referred to as model class MGSHSF in Vieli and Payne [2005]).

The ice divide and grounding line are, respectively, the first upstream and last downstream nodes in the model domain. The basal velocity solution is defined on grid nodes, and ice thickness, till properties, and temperature are defined on grid elements. Alongstream variations in horizontal basal velocity are calculated using the variational approach of Schoof [2006] applied to the force balance described in section 2.1. At each time step, we simultaneously solve for ice thickness and the grounding line position for the stretched domain using backward Euler implicit time integration. We also solve a transformed version of the temperature equation in the stretched domain, in which horizontal diffusion is neglected. See supporting information for all transformed equations and scaling arguments.

\section{Ice Stream Internal Variability}

In this section, we describe ice stream thermal oscillations and their similarity to variability produced in other models [Clarke, 1976; Fowler, 1987; MacAyeal, 1993; Payne, 1995; Fowler et al., 2001; Robel et al., 2013]. We also show that in a flowline model, transitions between stagnant and active phases of ice stream behavior are manifested as propagating activation and deactivation waves [Fowler and Schiavi, 1998]. Here, we advance previous work by demonstrating that activation waves propagate through a coupling of longitudinal stresses and frictional heat production. Using a sensitivity experiment, we suggest that numerical convergence of spatially resolved models of ice stream variability only occurs when the grid resolution is sufficiently fine $(\sim 1 \mathrm{~km})$ so as to capture the activation wave.

Going forward, we initialize experiments by running the flowline model to a converged state in which the ice stream is permanently streaming at moderate velocity. Our experiments then have an initialization period wherein the prescribed surface temperature is gradually decreased. The surface temperature and all other 


\begin{tabular}{|c|c|c|}
\hline Parameter & Description & Value \\
\hline$a_{c}$ & Accumulation rate $\left(\mathrm{m} \cdot \mathrm{yr}^{-1}\right)$ & 0.5 \\
\hline$b$ & Till empirical exponent & 21.7 \\
\hline$b_{0}$ & Ice divide bed height (m) & 100 \\
\hline$b_{x}$ & Bed slope & $-5 \times 10^{-4}$ \\
\hline$\hat{C_{i}}$ & Volumetric heat capacity of ice $\left(\mathrm{J} \cdot \mathrm{K}^{-1} \cdot \mathrm{m}^{-3}\right)$ & $1.94 \times 10^{6}$ \\
\hline$e_{c}$ & Till consolidation threshold & 0.5 \\
\hline$f$ & Buttressing parameter & 0 \\
\hline$g$ & Acceleration due to gravity $\left(\mathrm{m} \cdot \mathrm{s}^{-2}\right)$ & 9.81 \\
\hline$G$ & Geothermal heat flux $\left(W \cdot m^{-2}\right)$ & 0.07 \\
\hline$G_{s}$ & Lateral shear stress parameter $\left(\mathrm{kg} \cdot \mathrm{s}^{-4 / 3} \cdot \mathrm{m}^{-7 / 3}\right)$ & 400 \\
\hline$k_{i}$ & Thermal conductivity of ice $\left(\mathrm{J} \cdot \mathrm{s}^{-1} \cdot \mathrm{m}^{-1} \cdot \mathrm{K}^{-1}\right)$ & 2.1 \\
\hline$L_{f}$ & Specific latent heat of ice $\left(\mathrm{J} \cdot \mathrm{kg}^{-1}\right)$ & $3.35 \times 10^{5}$ \\
\hline$n$ & Nye-Glen Law exponent & 3 \\
\hline$T_{s}$ & Ice surface temperature $\left({ }^{\circ} \mathrm{C}\right)$ & -15 \\
\hline$z_{0}$ & Maximum available till thickness $(\mathrm{m})$ & 5 \\
\hline$\epsilon_{u}$ & Yield velocity $\left(\mathrm{m} \cdot \mathrm{s}^{-1}\right)$ & $10^{-9}$ \\
\hline$\kappa$ & Thermal diffusivity of ice $\left(\mathrm{m}^{2} \cdot \mathrm{s}^{-1}\right)$ & $1.41 \times 10^{-6}$ \\
\hline$\rho_{i}$ & Ice density $\left(\mathrm{kg} \cdot \mathrm{m}^{-3}\right)$ & 917 \\
\hline$\rho_{w}$ & Seawater density $\left(\mathrm{kg} \cdot \mathrm{m}^{-3}\right)$ & 1028 \\
\hline$\tau_{0}$ & Till empirical coefficient $(\mathrm{Pa})$ & $5.42 \times 10^{4}$ \\
\hline
\end{tabular}

system parameters (listed in Table 1 for the baseline simulation) are then held constant to allow the ice stream to equilibrate to the new parameter regime.

When either ice surface temperature or geothermal heat flux is high (as defined by the slope of the black line in Figure 1c), there will be an associated weak vertical temperature gradient at the bed. This enables a small negative background basal heat budget, which is augmented by a constant level of frictional heating and leads to a balanced basal heat budget $(m=0$ in equation (8)). This parameter regime produces "steady-streaming" behavior in an ice stream. However, if either ice surface temperature or geothermal heat flux is too low, frictional heating is not able to maintain a steady balance. This leads to repeated transitions between the active state where frictional heating causes excess meltwater production and the stagnant state where a shutdown in frictional heating causes meltwater to freeze. We refer to these transitions as "thermal oscillations."

We can compare the behavior of the simple box model of Robel et al. [2013] with the more complicated flowline model of this study. First, we see that the transition between steady-streaming behavior and thermal oscillations appears similar to the subcritical Hopf bifurcation in the simple model of Robel et al. [2013]. As a result, in simulations where a parameter is slowly varied through the stability boundary in both directions, there is hysteresis (Figures $\mathrm{la}$ and $\mathrm{lb}$ ). However, there are marked differences in the ice stream response depending on which parameter is varied. We see in Figure $1 \mathrm{~b}$ that despite the slowly applied variation in temperature $\left(6^{\circ} \mathrm{C}\right.$ over 50,000 years), a "memory" of past changes in ice surface temperature causes the ice stream to follow a different path during warming (red solid line) than it did during the initial cooling (blue dashed line), even upon returning to a steady-streaming state. Though variations in geothermal heat flux (Figure 1a) are immediately realized in the basal heat budget, variations in ice surface temperature (Figure $1 \mathrm{~b}$ ) are transported downward to the bed on a time scale of $10^{4}$ years. Thus, in addition to hysteresis, which is a general feature of parameter variation over the stability boundary, it is important to consider the time scale of ice stream adjustment to forcing through parameters such as ice surface temperature and accumulation. It is likely that both hysteresis and ice stream adjustment time scale play an important role in determining the response of ice streams to (relatively) rapid climate forcing both in modern and glacial periods. In section 6.2, we discuss the implications of hysteresis for interpretation of geomorphological features formed during deglacial transitions.

After a period of transient evolution, the ice stream reaches a stable behavior and we can determine whether it is in a steady-streaming or oscillatory state. Figure $1 c$ shows a representative set of simulations with prescribed surface temperature, $T_{s}$, and geothermal heat flux, $G$, varied over a reasonable range. These two parameters effectively span all possible types of ice stream behavior (see discussion of stability 

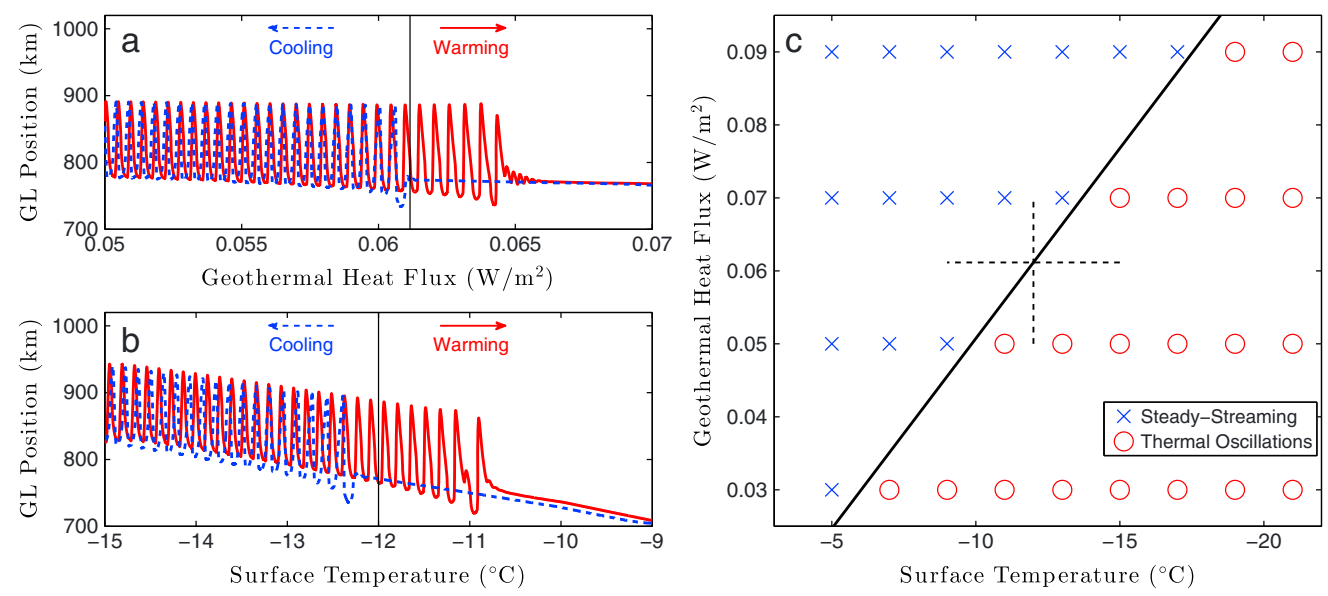

Figure 1. (a) Transient numerical simulation with slow $\left(4 \times 10^{-5} \mathrm{~W} \mathrm{~m}^{-2}\right.$ /century) decrease (blue dashed) and then increase (red solid) in geothermal heat flux. Surface temperature held constant at $T_{s}=-12^{\circ} \mathrm{C}$. Solid black line is the analytical stability boundary corresponding to solid black line in Figure 1c. (b) Transient numerical simulation with slow $\left(1.2 \times 10^{-2}{ }^{\circ} \mathrm{C} /\right.$ century) decrease (blue dashed) and then increase (red solid) in ice surface temperature. Geothermal heat flux held constant at $G=0.0612 \mathrm{~W} \mathrm{~m}^{-2}$. Solid black line is the analytical stability boundary corresponding to solid black line in Figure 1c. (c) A summary of model results in a parameter space of ice surface temperature and geothermal heat flux. Blue crosses are steady-streaming simulations (stable fixed point). Red circles are oscillatory simulations (stable limit cycle). Solid black line is an analytically derived stability boundary from Robel et al. [2013] with a correction for bed slope. See supporting information for details of parameter mapping and correction. Dashed black lines correspond to range of parameter variation for hysteresis simulations shown in Figures $1 \mathrm{a}$ and $2 \mathrm{~b}$. All other parameters are specified in Table 1.

in Robel et al. [2013, Figure 2]). The location of the analytically derived stability boundary of the simpler model (black line in Figure 1c) appears to predicts the transition between steady-streaming and oscillatory states simulated by the more complex flowline model of this study. Thermal oscillations have a minimum period of 700-1200 years near the subcritical stability boundary in the flowline model of this study, which also agrees with the simpler model of Robel et al. [2013]. This corresponds to a minimum amplitude of $50-100 \mathrm{~km}$ in grounding line migration.

The difference in complexity between the simple model of Robel et al. [2013] and the more complex model of this study hinders a direct mapping between their parameters (see further discussion in supporting information). However, the preponderance of similarities does suggest that at the very least, the simple model of Robel et al. [2013] can be useful in explaining the mechanisms underlying the behavior of more complex ice stream models.

\subsection{Thermal Oscillations}

The Hovmöller diagrams in Figure 2 show a single oscillation from a baseline simulation of an ice stream in a thermal oscillatory state. After a transient phase of initialization (0-10 kyr in this simulation), the ice stream reaches a new oscillatory state where it switches between active and stagnant phases. In the stagnant phase (Figure 3a), horizontal velocity is low in the ice stream trunk, ice surface slope is high near the grounding line, void ratio is low, part of the till layer thickness is frozen, and the basal temperature gradient is decreasing. Over time, the stagnant ice stream thickens, advection of cold ice to the bed is reduced, and basal temperatures warm through conduction, producing basal meltwater and weakening the bed. Activation occurs near the grounding line where the bed strength and lateral shear stress become less than the driving stress. In the active phase (Figure $3 b$ ), horizontal velocity is high everywhere, ice surface slopes are low, void ratio is high and basal temperature gradient is increasing. Over time, the active ice stream thins, increasing vertical heat conduction, freezing basal meltwater, and strengthening the bed. Stagnation occurs near the ice divide where the bed strength and lateral shear stress become greater than the driving stress. The entire process and the evolution of important system variables can be seen in the animation in the supporting information. This thermal mechanism is similar to that described in many previous studies [e.g., Robin, 1955; Oerlemans, 1982; MacAyeal, 1993; Payne, 1995]. 

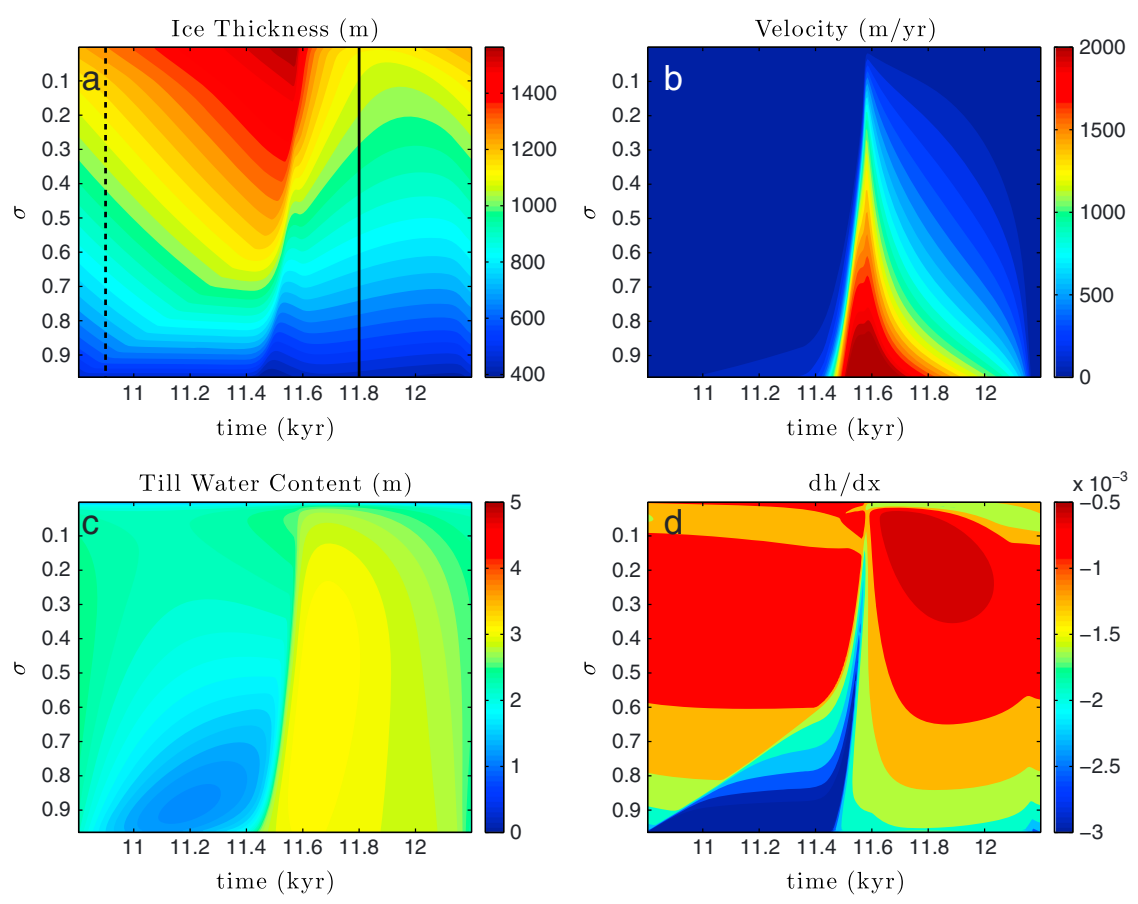

Figure 2. Hovmöller diagrams of a single ice stream thermal oscillation. Transient initialization occurs from 0 to $10 \mathrm{kyr}$. All panels are a function of time on $x$ axis and stretched alongstream coordinate, $\sigma$, on $y$ axis. (a) Ice thickness. (b) Basal horizontal velocity. (c) Till water content. (d) Ice thickness slope, $\frac{\partial h}{\partial x}$. In Figure 2a, dashed line indicates location of stagnant ice stream state snapshot corresponding to Figures $3 \mathrm{a}$ and $3 \mathrm{~b}$. Solid line indicates location of active ice stream state snapshot corresponding to Figures $3 \mathrm{c}$ and $3 \mathrm{~d}$.

Figure $2 \mathrm{~d}$ shows three "slope breaks" (rapid spatial changes in slope of ice thickness) away from the grounding zone, where there is always a slope break due to the transition to unconfined ice shelf flow. The concave slope break that separates nonsliding, steep upstream ice from fast-sliding, shallow downstream ice quickly propagates upstream during activation. This slope break is due to the transition from partially frozen to unfrozen till and is discussed in greater detail in the next section on activation waves.

During the stagnant phase, there is a prominent convex slope break that separates high-slope downstream ice from lower-slope upstream ice. Till is partially frozen everywhere in the ice stream, so nonzero velocities cannot be due to weak till. In this phase, there is some internal ice deformation occurring, but the predominant source of nonzero velocities downstream is slow sliding due to high driving stress (see Figure 3a). Longitudinal stresses ensure that the transition to a frictionless ice shelf always produces nonzero mass flux near the grounding line (even when the grounded bed is strong). By removing mass at the grounding line, the ice stream can produce a region of steep slope in the grounding zone, which produces large enough driving stress to match the high yield strength of a partially frozen bed $\left(\tau_{c}=\tau_{0}\right.$; see equation (12)). The transition from upstream ice below the yield stress to downstream ice at this yield stress corresponds to the transition between nonsliding and slow sliding, producing a slope break. This resembles the slope break near the grounding line of the stagnant Kamb Ice Stream [Catania et al., 2010].

During the active phase, there is a minor concave slope break that remains near the ice divide. As in the model of Schoof [2004], this slope break is the result of the imposed upstream boundary condition, which requires that the ice divide remains stagnant while the remainder of the ice stream is active.

\subsection{Activation Waves}

As is apparent from Hovmöller diagrams (Figure 2), ice stream activation does not occur simultaneously along the ice stream length but rather begins near the grounding zone and then propagates upstream as an activation wave. This wave is defined by a sharp transition in ice thickness, till water content, and horizontal velocity. As it propagates upstream, ice surface slopes decrease, frictional heating increases, till thaws, void ratio increases, and horizontal velocity increases by 2 orders of magnitude. 

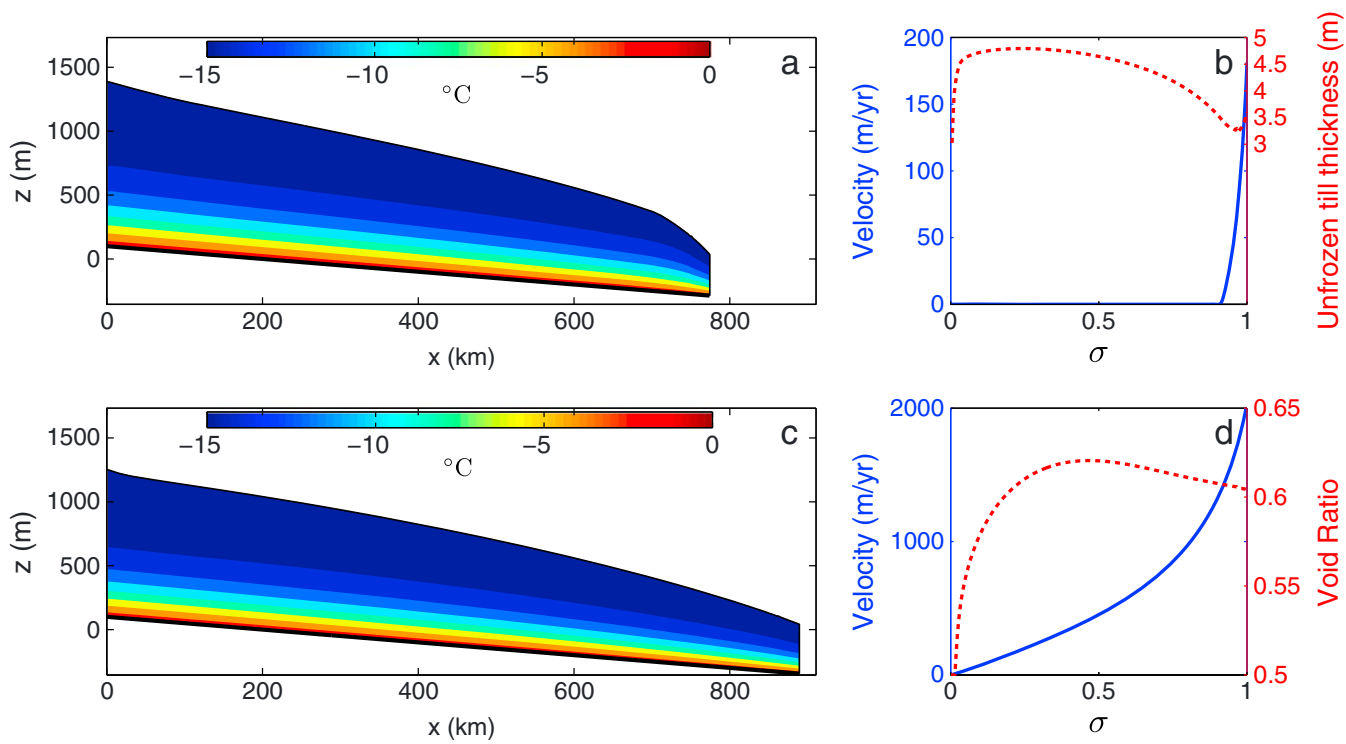

Figure 3. Snapshots of ice stream stagnant state $(t=10.9 \mathrm{kyr}$ in Figure 2$)$ and active state $(t=11.8 \mathrm{kyr}$ in Figure 2$)$ from thermal oscillatory regime run described in section 3. (a) Side view of stagnant ice stream, contours indicate ice temperature. (b) Horizontal basal velocity (blue solid line) and unfrozen till thickness (red dashed line; void ratio is at lower consolidation threshold, $e_{c}$ everywhere) of stagnant ice stream as a function of $\sigma$ alongstream coordinate. Maximum available till layer thickness is 5 meters. (c) Side view of active ice stream, contours indicate ice temperature. (d) Horizontal basal velocity (blue solid line) and till void ratio (red dashed line) of active ice stream as a function of $\sigma$ alongstream coordinate.

We show here that the mechanism of activation wave propagation is a coupling between frictional heat production and longitudinal stress. At a location where a perturbation of high ice velocity is initiated due to a weak bed, longitudinal stress smooths variations in horizontal velocity. This produces ice slip over a strong bed up and downstream of the initial perturbation, resulting in frictional heat production. This initiates a positive feedback between frictional heating, meltwater production, bed weakening, and increased ice velocity. The adjacent till is quickly saturated, and horizontal propagation continues as longitudinal stress spreads high velocities from the newly weakened bed. An equivalent "deactivation wave" occurs near the ice divide, but it does not propagate the full ice stream length before complete stagnation occurs. Though this was explored to some extent in Fowler and Schiavi [1998], we will not discuss it here in detail.

In Figure $4 b$, during the stagnant phase, we see a zone of large positive longitudinal stress that corresponds with a slope break. This longitudinal stress maximum slowly moves upstream with the slope break, initiating infinitesimal sliding up and downstream, where the till is still strong. The aforementioned propagation mechanism should be initiated, but the net heat flux at the bed due to geothermal heat flux and vertical heat conduction is negative (Figure 4e) and small perturbations in frictional heat production are rapidly dissipated. When the net heat flux at the bed crosses zero due to ongoing accumulation of ice thickness, perturbations in frictional heating are able to rapidly grow through the positive feedback of frictional heating and meltwater production (Figure 4c). We have plotted an example (Figures $4 \mathrm{~d}$ and $4 \mathrm{e}$ ) at $\sigma=0.5$, in the middle of the ice stream, where the net heat flux crosses zero at $t \approx 11.45 \mathrm{kyr}$, several decades before there is a spike in both longitudinal stress and frictional heat production. In such a way, the activation wave propagates via coupling of frictional heating and longitudinal stress, but only when the background net heat flux allows for the growth of the frictional heating instability.

Price et al. [2008] showed a similar feedback between longitudinal stress and frictional heating in experiments of an externally perturbed ice stream model without meltwater storage. In Price et al. [2008] and other similar studies [Payne et al., 2004], initial perturbations near the grounding line propagate upstream while being rapidly damped, typically not reaching further than $100-200 \mathrm{~km}$. In this study, the initiation of streaming at the grounding line is amplified and propagated $\sim 1000 \mathrm{~km}$ upstream to the ice divide, where it is damped only because of the prescription of no sliding. The frictional heating instability described 

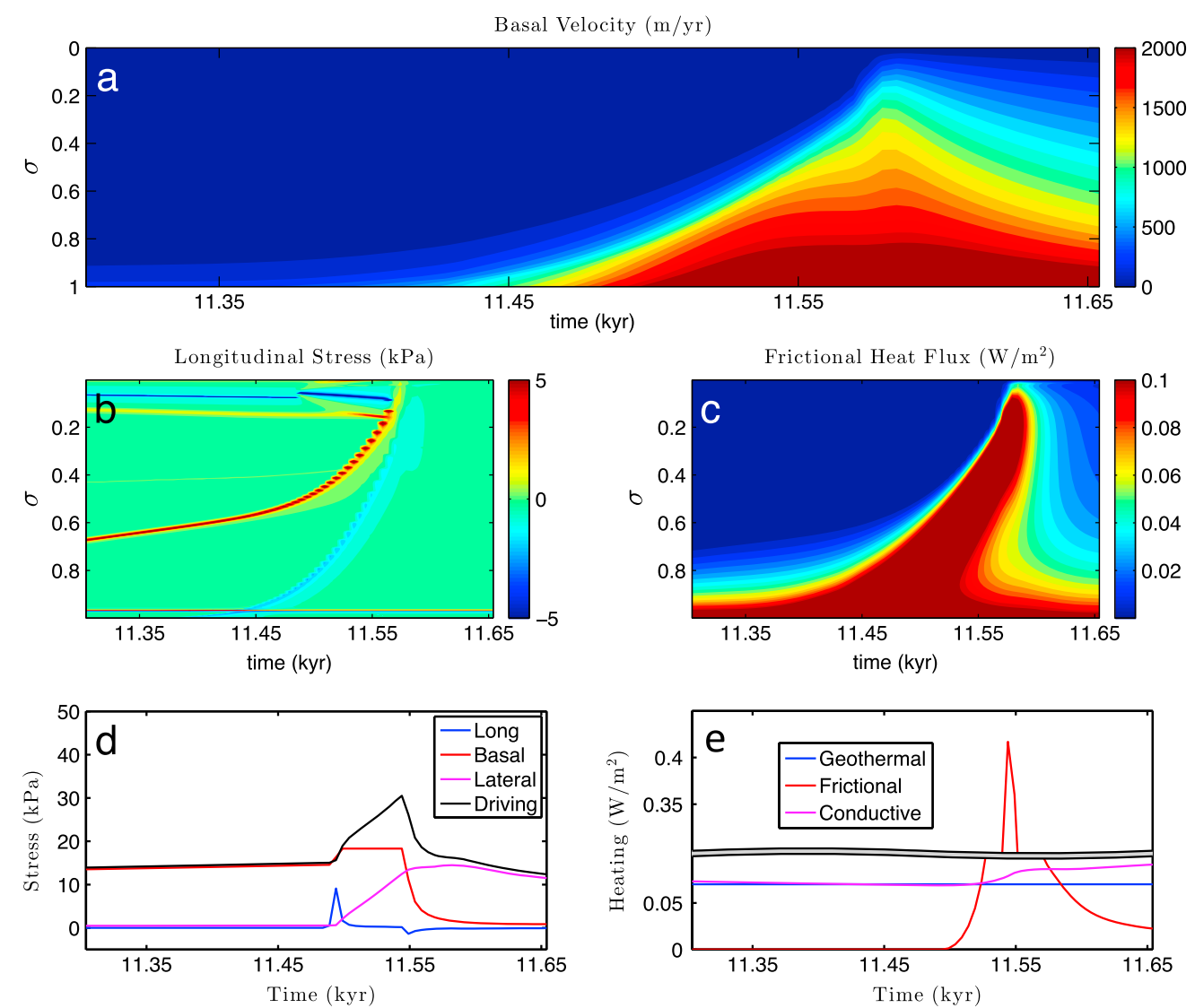

Figure 4. Mechanism of activation wave propagation. (a-c) Hovmöller diagrams with time on the $x$ axis and stretched alongstream coordinate, $\sigma$, on $y$ axis. (a) Horizontal basal velocity. (b) Longitudinal stress. (c) Frictional heat flux. (d) Force balance and (e) basal heat budget at a single location $(\sigma=0.5)$ with time on the $x$ axis. In Figure 4e, we plot the negative of the conductive heat flux and split the $y$ axis to highlight the difference in geothermal and vertical conductive heat flux.

previously is the physical mechanism responsible for amplification. However, it is the storage of meltwater in the till layer which maintains weak till long after passage of the activation wave. Sensitivity experiments (Table 2 ) demonstrate that as we increase the maximum available till thickness $\left(Z_{0}\right)$, which controls the rate of till layer adjustment to changes in basal meltwater production, the amplitude of grounding line migration associated with thermal oscillations also increases. Thus, the "memory" maintained by the storage of meltwater ultimately controls the integrated ice stream response to activation waves. This agrees with the speculation of Price et al. [2008] that when basal storage capacity is significant, the enduring effect of past meltwater production enhances the ice stream response to changes near the grounding line.

The growth rate and extent of inland propagation is also dependent on the initial ice stream state. Ice streams that begin in a stagnant state amplify perturbations aggressively due to the significant contrast between stagnant and adjacent active ice. Ice streams that begin in a streaming state (as in Price et al. [2008]) may damp perturbations due to the lesser contrast between streaming and adjacent slightly faster streaming ice (and hence weaker longitudinal stress gradient). Though this study is focused on understanding the unforced variability of ice streams, these simulations suggest that further study of activation waves and their representation in numerical models would advance understanding of the magnitude, time scale, and upstream extent of the ice stream response to forcing near the grounding line.

\subsection{Activation Wave Smoothness and Model Convergence}

Activation waves are a common feature of longitudinally resolved ice sheet models with simple basal hydrology [Fowler, 1987; Greenberg and Shyong, 1990; Payne, 1995; Fowler and Schiavi, 1998]. Similarly, in many model simulations of large paleo-ice sheet discharge events (i.e., Heinrich events) [see Calov et al., 2002; Papa et al., 2006; Calov et al., 2010], wave-like features do appear. Notwithstanding the qualitative 


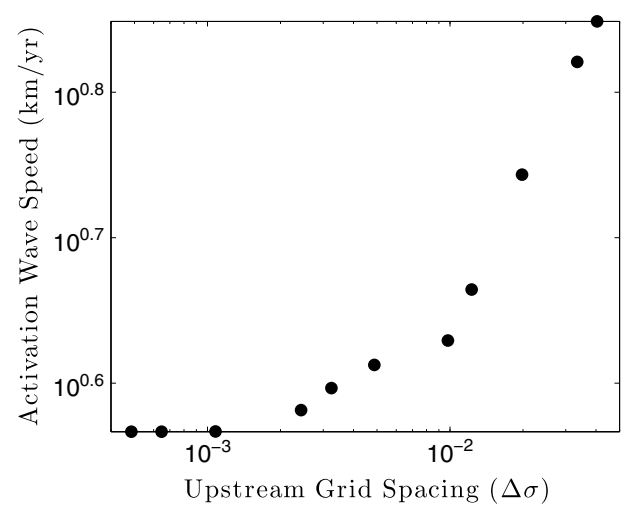

Figure 5. Activation wave speed convergence with finer upstream horizontal grid spacing. $X$ axis is grid spacing measured in non-dimensional stretch coordinate units (in text, we refer to physical units of grid spacing corresponding to an ice stream with $x_{g}=1000 \mathrm{~km}$ for simplicity). Activation wave speed is calculated by tracking the movement of the concave slope break referenced in section 3.1 from the grounding zone to a location $x_{g} / 10$ from ice divide. resemblance of these features to activation waves, proper implementation of a basal hydrology scheme is critical to ensuring realistic activation wave behavior and model convergence. As both Payne [1995] and Fowler and Schiavi [1998] argued, models with instantaneous "switches" in sliding and no longitudinal stress will produce shock-like activation waves that are difficult to resolve and prone to numerical errors. Fowler and Schiavi [1998] fixed this problem by including an ad hoc bed relaxation time scale that smooths the transition from non-sliding to sliding ice. In our model, the inclusion of longitudinal stresses and storage of meltwater in till (which has an intrinsic bed relaxation time scale captured by the non-dimensional parameter $\alpha$ derived in Robel et al. [2013]) smooths the transition between non-sliding and sliding ice. Hence, the inclusion of some key physical processes associated with realistic ice streams mitigates the numerical issue of shock-like activation waves.

Fowler and Schiavi [1998] showed that matched asymptotic methods can be used to analyze activation waves in shock coordinates. Repeating such an asymptotic analysis for our more complex model is beyond the scope of our study. We instead test the sensitivity of simulated activation wave speed to upstream model resolution (grounding zone resolution is already high) to determine whether it is necessary to resolve the boundary layer associated with the activation wave front (Figure 5). At a coarse upstream horizontal grid spacing of $\sim 50 \mathrm{~km}$ typical of continental-scale ice sheet models, activation wave speed is approximately twice its fully converged value. At much finer upstream resolution of $\sim 5 \mathrm{~km}$, activation waves are within $10 \%$ of fully converged. Further convergence proceeds slowly with increased resolution, but we are confident that our solution has reached numerical convergence (within 1\%) for fine grid spacing of $\sim 1 \mathrm{~km}$. Convergence in activation wave speed is also accompanied by convergence of thermal oscillation amplitude and period. We conclude that accurate simulation of ice stream variability (including Heinrich events) requires considerably finer horizontal grid resolution than what has traditionally been used in coarse-gridded (25-150 km) ice flow models at continental scale [Calov et al., 2002; Papa et al., 2006; Calov et al., 2010]. This can likely be accomplished with a hybrid model scheme [Bueler and Brown, 2009] or adaptive-mesh approaches [e.g., Goldberg et al., 2009].

\subsection{Activation Wave Propagation to the Grounding Line}

In the simulation discussed here, steep surface slopes maintain nonnegligible sliding velocities in the grounding zone which produce a constant level of frictional heat production, even during the stagnant phase. Consequently, in this model, the heat budget becomes positive and activation occurs near the grounding line first. This does not imply that activation waves only propagate upstream, as related observational [Fatland and Lingle, 1998] and theoretical [Fowler, 1987] analyses show that mountain glacier surges (which are due to a similar mechanism) propagate both upstream and downstream. In this study, it is difficult to discern the downstream-propagating activation wave, as it reaches the grounding line very quickly. Upon reaching the grounding line, this activation wave initiates a short-lived decrease in ice thickness, and attendant grounding line retreat (see black solid line of Figure 6a). The influence of the downstream-propagating activation wave is quickly overtaken by transport from the upstream-propagating activation wave which initiates a significantly larger increase in ice thickness and attendant grounding line advance. We discuss this grounding line migration in the next section.

\section{Grounding Line Migration}

Thermal oscillations in our ice stream model are accompanied by large, rapid migrations in grounding line position (black solid line in Figure 6a). When the ice stream activates, the grounding line begins to advance 
at rates that can exceed $1 \mathrm{~km} / \mathrm{yr}$, with most of the advance then occurring over a period of 100-300 years. Grounding line retreat begins during the active phase after excess ice thickness in the grounding zone has been transported through the grounding line. Grounding line retreat at rates of hundreds of meters per year then continues for the remainder of the active phase. When the ice stream stagnates, the rate of retreat decreases significantly and the grounding line position becomes nearly static. For a range of parameters appropriate for the Siple Coast (see Table 2), the grounding line can migrate 100-170 km over the thermal oscillation cycle. To explain this sequence of grounding line migration events, we examine the advection of mass within and out of the ice stream in more detail.

During the stagnant phase, the bed is strong and supports steep surface slopes in a downstream portion of the ice stream, as a significant reservoir of mass is stored upstream. When activation occurs, there is a large divergence in ice velocity near the grounding line (black solid line in Figure $6 \mathrm{~b}$ ) associated with the initiation of the upstream propagating activation wave. As the activation wave propagates upstream, it advects ice thickness from the upstream ice mass reservoir to the grounding line. As we argue below, the flotation condition (equation (6)) ensures that any changes in grounding line ice thickness lead to grounding line migration. As ice is advected to the grounding line from upstream, a nearly equivalent effective grounding line flux (red dotted line in Figure $6 \mathrm{~b}$ ) will remove ice from the grounded ice stream. The effective grounding line flux, $\tilde{q}_{g,}$, is calculated as $\left[u\left(x_{g}\right)-\dot{x}_{g}\right] h\left(x_{g}\right) . \tilde{q}_{g l}$ accounts both for ice advected through the grounding line and the contribution from a change in the size of the domain (the grounding line in this model), making it the relevant measure of ice leaving the system. In this case, the effective grounding line ice flux does not adjust rapidly enough to compensate for the significant mass flux from upstream and therefore ice thickness in the grounding zone increases, leading to grounding line advance.

As the grounding line position advances, the effective grounding line flux increases with the deepening bed. Eventually, effective grounding line flux exceeds the influx of mass from upstream, leading to a decrease in ice thickness and grounding line retreat. Once the ice stream stagnates, slow advection of ice from the grounding zone continues primarily through slow sliding, which continues for the duration of the stagnant interval until reactivation. Keeping in mind the highly idealized nature of these model simulations (and that they represent an order-of-magnitude estimate of ice flux for a real ice stream system), we can approximate the sea level contribution of internal variability for the Siple Coast-like baseline ice stream simulation. At the peak of ice streaming, the equivalent rate of mass discharge through the grounding line is approximately $0.15 \mathrm{~mm} / \mathrm{yr}$ and the total mass flux through the grounding line over the course a single thermal oscillations is $85 \mathrm{~mm}$ (for an ice stream $50 \mathrm{~km}$ wide at the grounding line, with ice flux spread evenly over global ocean area).

The scale of change in grounding line position resulting from thermal oscillations is determined by ice thickness at the grounding line, where ice begins to float (equation (6)). This flotation condition can be written in difference form

$$
\rho_{i} \frac{\Delta h_{g}}{\Delta x_{g}}=\rho_{w} b_{x}
$$

and then rearranged as

$$
\Delta x_{g}=\frac{\rho_{i}}{\rho_{w} b_{x}} \Delta h_{g}
$$

where $b_{x}$ is the local bedslope over the region of grounding line migration, $\Delta h_{g}$ is a change in ice thickness at the grounding line and $\Delta x_{g}$ is a change in grounding line position. A straightforward interpretation is that changes in grounding line position are determined by changes in the ice thickness at the grounding line, modulated by the inverse of the local bedslope. This is confirmed by Figure $6 \mathrm{a}$, where the net mass balance in the grounding zone (blue dashed line; defined as $\Delta \sigma x_{g} a_{c}+(u h)_{\sigma=1-\Delta \sigma}-(u h)_{\sigma=1}$ with $\Delta \sigma=0.03$ ) is proportional to the derivative of the grounding line position. When the net mass balance in the grounding zone is positive, the grounding line thickness is increasing and the grounding line advances. Conversely, when the net mass balance in the grounding zone is negative, the grounding line thickness decreases and the grounding line retreats. For the same change in ice thickness at the grounding line, a shallower bed slope will lead to more grounding line migration. This is confirmed by experiments of sensitivity to bed slope shown in Table 2. 

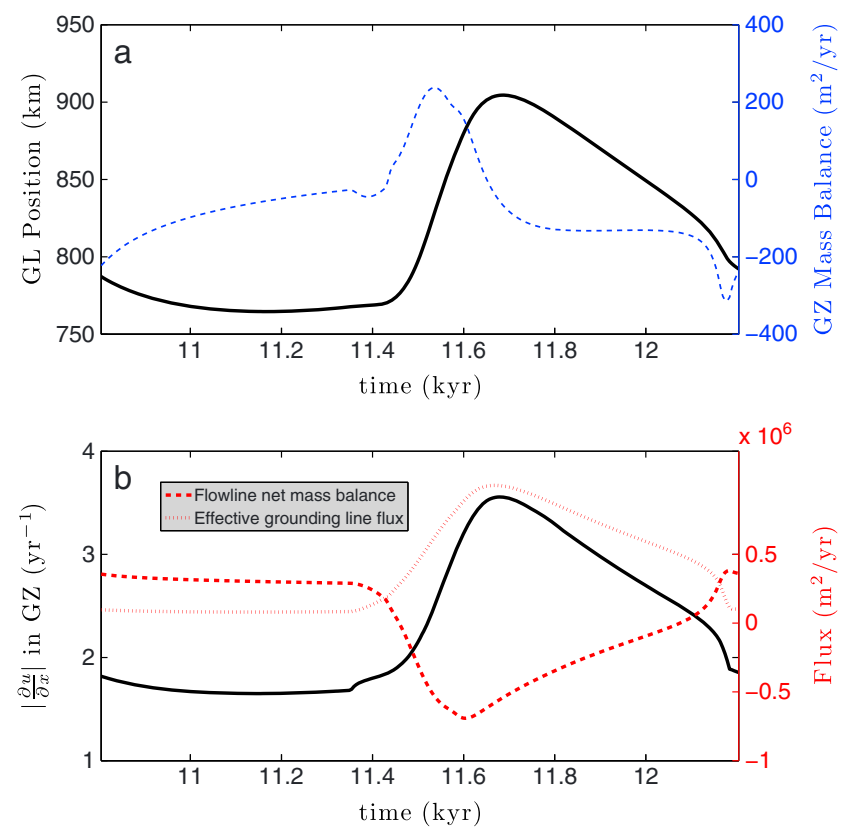

Figure 6. Time series of grounding line state over one thermal oscillation. (a) Solid black line is grounding line position. Dashed blue line is net mass balance over the grounding zone, defined as $\Delta \sigma x_{g} a_{c}+(u h)_{\sigma=1-\Delta \sigma}-(u h)_{\sigma=1}$ with $\Delta \sigma=0.03$. (b) Solid black line is average velocity divergence over grounding zone. Dashed red line is the net mass balance for the entire ice stream flowline domain. Dotted red line is the effective grounding line flux: $\tilde{q}_{g l}=\left[u\left(x_{g}\right)-\dot{x}_{g}\right] h\left(x_{g}\right)$. Time is on the $x$ axis for both panels.
In our simulations of an ice stream on a linear prograde bed with no external forcing, the grounding line position repeatedly migrates over a significant distance in response to an internal instability unrelated to the marine ice sheet instability (as first described by Weertman [1974]). Nearly all of the grounding line advance and retreat in our model occurs during the active phase, when the total ice stream mass balance is negative. During the stagnant phase, the ice stream mass balance is positive and a reservoir of mass grows upstream. However, the net mass balance of the grounding zone is small and negative, and the grounding line continues to slowly retreat during the stagnant phase. The local mass balance in the grounding zone (blue dashed line in Figure 6a) has a more direct relationship to the grounding line migration rate through its influence on ice thickness than the net mass balance over the full ice stream length (red dashed line in Figure 6b). This has important consequences

for the interpretations of grounding line migration that associate advance with a positive ice stream mass balance and retreat with negative mass balance [e.g., Shabtaie and Bentley, 1987; Joughin and Tulaczyk, 2002]. Ice streams that are currently in retreat are likely to have negative mass balance in the vicinity of the grounding zone. However, a retreating grounding line does not always necessitate a negative mass balance in the entire ice stream, as we have shown through the example of unforced variability produced by thermal oscillations.

\section{Parameter Sensitivity}

We assess the robustness of the simulated ice stream behavior with a basic sensitivity analysis, varying parameters from the baseline simulation. The results of these parameter sensitivity tests are compiled in Table 2 and are meant to sample a range of values that could reasonably be expected for Siple Coast ice streams. Generally, these simulations exhibit thermal oscillations with amplitude of grounding line migration of $100-170 \mathrm{~km}$ and a period of $900-1800$ years.

Reductions in either ice surface temperature or geothermal heat flux lead to an increase in the amplitude of upstream thickness variations associated with thermal oscillations. This agrees with Robel et al. [2013], who predict an increase in amplitude of ice stream thickness oscillations for decreasing ice surface temperature or geothermal heat flux. Counterintuitively, this increase in the amplitude of upstream thickness oscillations results in a decrease in the amplitude of grounding line migration associated with thermal oscillations. As it turns out, when the ice stream activates, the rate of ice transport downstream to the grounding line is reduced by increased lateral stress (see last term on right hand side of equation (1)) due to thicker ice in the upstream mass reservoir. The slower delivery of ice to the grounding due to increased lateral shear stress is more effectively compensated by the effective grounding line flux, resulting in less ice thickening at the grounding line and thus less grounding line migration.

A wider ice stream decreases lateral shear stress $\left(G_{s}\right)$ and leads to an increase in thermal oscillation amplitude, but a decrease in period. The reduced period is caused by a lower threshold for activation of stagnant 
Table 2. Compilation of Results From Parameter Sensitivity Experiments ${ }^{a}$

\begin{tabular}{|c|c|c|c|c|c|c|}
\hline \multirow[b]{2}{*}{ Parameter } & \multicolumn{3}{|c|}{ Decreased from baseline } & \multicolumn{3}{|c|}{ Increased from baseline } \\
\hline & Value & Amplitude (km) & Period (year) & Value & Amplitude (km) & Period (year) \\
\hline$T_{s}$ & -20 & 120 & 1297 & -10 & $x$ & $x$ \\
\hline G & 0.05 & 119 & 1306 & 0.10 & $x$ & $x$ \\
\hline$a_{c}$ & 0.4 & 152 & 1714 & 0.6 & 135 & 1190 \\
\hline$b_{x}$ & $-4 \times 10^{-4}$ & 159 & 1560 & $-6 \times 10^{-4}$ & 130 & 1390 \\
\hline$G_{s}$ & 300 & 153 & 1314 & 450 & $x$ & $\mathrm{X}$ \\
\hline$Z_{0}$ & 1 & 104 & 912 & 7 & 165 & 1570 \\
\hline$f$ & - & - & - & 0.5 & $x$ & $x$ \\
\hline
\end{tabular}

${ }^{a}$ Simulations marked with an " $\mathrm{X}$ " exhibit steady-streaming behavior. Other parameter values are the same as the baseline simulation and are listed in Table 1. Baseline simulation has amplitude $137 \mathrm{~km}$ and period 1382 years.

ice streams. When the ice stream activates, reduced lateral stress allows for larger excursions in grounding line position.

Increasing the buttressing parameter (from the baseline of an unbuttressed ice stream where $f=0$ ) has the ability to reduce amplitude and period or altogether suppress thermal oscillations (marked with " $X$ " in Table 2). This may be an important consideration in applying this model to buttressed ice streams. However, it is unclear what value of the buttressing parameter would be appropriate for real Siple Coast ice streams. As the results in Table 2 show, there are other cases in which the stability boundary has been crossed resulting in steady-streaming behavior. This leads us to the same conclusion as Robel et al. [2013] that modern Siple Coast ice streams may reside in a parameter regime on or near a transition to steady-streaming behavior.

\section{Relevance to Observations and Other Models}

As the parameter sensitivity experiments of section 5 show, comparing the results of this idealized model to real observations can be complicated by a number of factors including ice shelf buttressing and spatial variations in ice stream width, bed topography, accumulation, and ice surface temperature. Additionally, Horgan and Anandakrishnan [2006] and Rignot et al. [2011] suggested that there is an error of hundreds of meters per year in modern estimates of grounding line migration rates in the Siple Coast. The short duration of reliable grounding line observations from aircraft and satellites hinders robust detection of low-frequency signals amid high-frequency noise and potentially significant external forcing. Thus, it is difficult to discern ongoing grounding line migration during most of the thermal oscillation cycle, except in the period immediately following activation and the period surrounding stagnation when migration rates are sufficiently large to distinguish from measurement error. Correspondingly, this section focuses on geological indicators of long-term grounding line migration and their correspondence to model simulations from this and other studies.

\subsection{Whillans and Kamb Ice Streams}

Luthra et al. [2013] found evidence of multiple subglacial sediment packages $\sim 80 \mathrm{~km}$ upstream of the modern grounding line of Whillans Ice Stream. These features may have originated from sediment deposition at the grounding line during multiple past retreat and re-advance events. We would expect that the current ongoing deceleration and eventual stagnation would result in grounding line migration to the location of these features. This broadly agrees with Catania et al. [2010], who, on the basis of melt-related stratigraphy, concluded that the grounding line of Whillans Ice Stream has retreated and readvanced coinciding with stagnation and reactivation over the last 850 years.

Thomas et al. [1988] and Horgan and Anandakrishnan [2006] agree that the grounding line of recently stagnant Kamb Ice Stream is static or migrating at a slow rate. Catania et al. [2005] inferred the presence of a relict grounding line $\sim 100 \mathrm{~km}$ upstream of the current grounding line, which may be evidence of past thermal oscillations. Paired with our simulation, one potential interpretation is that Kamb Ice Stream is currently in a period of slow post-stagnation retreat to the location of that relict grounding line. However, this simulation does not account for the fact that the grounding line of Kamb Ice Stream currently lies on a retrograde section of an overdeepening. Another possibility is that the grounding line of Kamb Ice Stream 
is currently located at a lateral "pinning point" where lateral shear stresses associated with narrowing has prevented further retreat [Dupont and Alley, 2006]. Under this scenario, future retreat associated with stagnation may occur rapidly, once the grounding line has passed its current location. Accounting for longitudinal variations in width and bed topography would enable the flowline model to test such hypotheses.

\subsection{Grounding Zone Wedges}

Grounding zone wedges are widespread features of the Antarctic continental shelf in locations where paleo-ice streams retreated during the last deglaciation [Livingstone et al., 2012]. In many instances, these grounding zone wedges are found in clusters [Mosola and Anderson, 2006; Graham et al., 2010] or interspersed with push moraines [O'Brien et al., 1999], indicating episodic grounding line retreat and re-advance. Studies have suggested a number of possible mechanisms for generating these depositional features, such as changes in external forcing [Hollin, 1962], lateral pinning points [Jamieson et al., 2012], or subglacial drainage events [Livingstone et al., 2012].

It is possible that grounding line migration due to the type of internal ice stream variability simulated in this study was superimposed on gradual retreat of ice streams during the last deglaciation. The simulations shown in this study suggest that there are periods of near-zero grounding line migration associated with both the stagnant phase and the peak of the active phase of an ice stream thermal oscillation. These appear to be sufficiently long to produce grounding zone wedges observed on the Antarctic continental shelf. Such an interpretation is supported by Christoffersen et al. [2010], who suggested that sediment wedges and other geological features may be the result of subsequent melting and refreezing of basal ice debris.

The stability boundary hysteresis described in section 3 may have important implications for interpretations of geological features formed during periods of known climate transition. All else being equal, atmospheric warming associated with a deglacial transition could cause a retreating ice stream to transition from a thermal-oscillatory state which may produce clusters of grounding zone wedges during periods of stagnation to a steady-streaming state which may not produce a grounding zone wedge. This explanation is supported by observational evidence that at least four Antarctic paleo-ice streams underwent episodic retreat on the outer continental shelf and then fast retreat on the inner continental shelf during the last deglaciation [Livingstone et al., 2012]. Subsequent cooling associated with the buildup of a large ice sheet would cause the reverse transition, but not at the same location on the shelf. The presence of such hysteresis in ice stream behavior could be revealed by careful analysis of geological features (barring significant overprinting) near the margins of paleo-ice sheets. This is just one example of how using the ice stream model of this study in conjunction with estimates of topography and paleoclimatological forcing could be a powerful tool in interpreting the location and age of paleo-ice stream geomorphological features.

\subsection{Comparison to Other Model Studies}

The data-model studies of Hulbe and Fahnestock [2004, 2007], and Fried et al. [2014] provide the best comparison for simulations of grounding line migration induced by ice stream variability. The models used in these studies include prescribed ice stream variability forcing a domain that primarily encompasses the Ross Ice Shelf. The resulting grounding line migration looks broadly similar to the simulations in our study, including slow grounding line retreat during stagnation and advance after activation. Hulbe and Fahnestock [2007] highlights a $500 \mathrm{~m} / \mathrm{yr}$ retreat of the grounding line of Kamb Ice Stream following the recent stagnation. This estimate seems large compared to observations of the grounding line retreat of Kamb Ice Stream and our prediction, though it is possible that more realistic forcing and topography could yield such rapid grounding line retreat.

Our model serves as a complement to the analysis of Hulbe and Fahnestock [2004, 2007]. We have improved on these earlier studies by simulating the grounding zone at a sufficiently high resolution to resolve the mechanical transition from ice sheet to ice shelf flow [Schoof, 2007a]. This gives us confidence that the type of simulated transient behavior of the grounding line during periods of significant change is reasonable. Additionally, the transport of significant ice thickness to the grounding line during the active phase enables the rapid grounding migration simulated in our model. These dynamics cannot necessarily be realistically reproduced by simply prescribing ice stream variability. By including ice stream thermodynamics and the evolution of till properties, we have a closed system that does not require external forcing to 
Acknowledgments

This work has been supported by the NSF grant AGS-1303604 (A.R. and E.T.). E.T. thanks the Weizmann Institute for its hospitality during parts of this work. A.R. has been supported by the NSF Graduate Research Fellowship. C.S. has been supported by NSERC Discovery Grant 357193-08. We thank Marianne Haseloff, Ian Eisenman, Richard Katz, and two anonymous reviewers for useful suggestions and helpful conversations during the completion of this work. All model results used to produce the figures in this study, and flowline model code is available from the corresponding author upon request. produce grounding line migrations. This enables us to describe the physical links between thermal oscillations, the development of activation waves, and migration of the grounding line.

\section{Conclusions}

In this study, we have developed reasonable estimates for the time scale and amplitude associated with thermally induced grounding line variability. This modeled variability is broadly similar to simpler ice stream models, demonstrating their usefulness as explanatory tools. Activation waves propagate outward from an initial location near the grounding line. A sensitivity analysis demonstrates that accurately modeling thermal oscillations and their associated activation wave requires a resolution of $\sim 1 \mathrm{~km}$. The activation wave triggers grounding line migration that can exceed $100 \mathrm{~km}$ at rates over $1 \mathrm{~km} / \mathrm{yr}$. In the example shown in this study, grounding line migration is the result of changes in mass balance at the grounding line, which may be different from the total ice stream mass balance. Additionally, these simulations have been used to broadly interpret observations of past ice stream grounding line migration. We conclude that modeling of specific ice streams with this approach may assist in interpretation of seemingly disparate observations of grounding line migration.

\section{References}

Alley, R., D. Blankenship, C. Bentley, and S. Rooney (1986), Deformation of till beneath ice stream B, West Antarctica, Nature, 322(6074), 57-59.

Anandakrishnan, S., G. Catania, R. Alley, and H. Horgan (2007), Discovery of till deposition at the grounding line of Whillans Ice Stream, Science, 315(5820), 1835-1838.

Bamber, J., D. Vaughan, and I. Joughin (2000), Widespread complex flow in the interior of the Antarctic ice sheet, Science, 287(5456), 1248-1250.

Bennett, M. (2003), Ice streams as the arteries of an ice sheet: Their mechanics, stability and significance, Earth Sci. Rev., 61(3-4), 309-339, doi:10.1016/S0012-8252(02)00130-7.

Blankenship, D., C. Bentley, S. Rooney, and R. Alley (1986), Seismic measurements reveal a saturated porous layer beneath an active Antarctic ice stream, Nature, 322(6074), 54-57.

Bougamont, M., S. Tulaczyk, and I. Joughin (2003a), Numerical investigations of the slowdown of Whillans ice stream, West Antarctica: Is it shutting down like ice stream C?, Ann. Glaciol., 37(1), 239-246.

Bougamont, M., S. Tulaczyk, and I. Joughin (2003b), Response of subglacial sediments to basal freeze-on: 2 . Application in numerical modeling of the recent stoppage of Ice Stream C, West Antarctica, J. Geophys. Res., 108(B4), 2223, doi:10.1029/2002JB001936.

Bougamont, M., S. Price, P. Christoffersen, and A. Payne (2011), Dynamic patterns of ice stream flow in a 3-D higher-order ice sheet model with plastic bed and simplified hydrology, J. Geophys. Res., 116, F04018, doi:10.1029/2011JF002025.

Bueler, E., and J. Brown (2009), Shallow shelf approximation as a "sliding law" in a thermomechanically coupled ice sheet model, J. Geophys. Res., 114, F03008, doi:10.1029/2008JF001179.

Calov, R., A. Ganapolski, V. Petoukhov, M. Claussen, and R. Greve (2002), Large-scale instabilities of the Laurentide ice sheet simulated in a fully coupled climate-system model, Geophys. Res. Lett., 29 (24), 2216, doi:10.1029/2002GL016078.

Calov, R., et al. (2010), Results from the Ice-Sheet Model Intercomparison Project-Heinrich Event INtercOmparison (ISMIP HEINO), J. Glaciol., 56(197), 371-383.

Catania, G., H. Conway, R. CF, and T. Scambos (2005), Surface morphology and internal layer stratigraphy in the downstream end of Kamb Ice Stream, West Antarctica, J. Glaciol., 51(174), 423-431.

Catania, G., C. Hulbe, and H. Conway (2010), Grounding-line basal melt rates determined using radar-derived internal stratigraphy, J. Glaciol., 56(197), 545-554.

Catania, G., C. Hulbe, H. Conway, T. Scambos, and R. CF (2012), Variability in the mass flux of the Ross ice streams, West Antarctica, over the last millennium, J. Glaciol., 58(210), 741-752.

Christoffersen, P., S. Tulaczyk, and A. Behar (2010), Basal ice sequences in antarctic ice stream: Exposure of past hydrologic conditions and a principal mode of sediment transfer, J. Geophys. Res., 115, F03034, doi:10.1029/2009JF001430.

Clarke, G. (1976), Thermal regulation of glacier surging, J. Glaciol., 16(74), 231-250.

Cornford, S. L., D. F. Martin, D. T. Graves, D. F. Ranken, A. M. Le Brocq, R. M. Gladstone, A. J. Payne, E. G. Ng, and W. H. Lipscomb (2013), Adaptive mesh, finite volume modeling of marine ice sheets, J. Comput. Phys., 232(1), 529-549.

Dowdeswell, J., D. Ottesen, J. Evans, C. Cofaigh, and J. Anderson (2008), Submarine glacial landforms and rates of ice-stream collapse, Geology, 36, 819-822.

Dupont, T., and R. Alley (2005), Assessment of the importance of ice-shelf buttressing to ice-sheet flow, Geophys. Res. Lett., 32, L04503, doi:10.1029/2004GL022024.

Dupont, T. K., and R. B. Alley (2006), Role of small ice shelves in sea-level rise, Geophys. Res. Lett., 33, L09503, doi:10.1029/2005GL025665.

Engelhardt, H., N. Humphrey, B. Kamb, and M. Fahnestock (1990), Physical conditions at the base of a fast moving Antarctic ice stream, Science, 248(4951), 57-59.

Fahnestock, M., T. Scambos, R. Bindschadler, and G. Kvaran (2000), A millennium of variable ice flow recorded by the Ross Ice Shelf, Antarctica, J. Glaciol., 46(155), 652-664.

Fatland, D., and C. Lingle (1998), Analysis of the 1993-5 Bering Glacier (Alaska) surge using differential SAR interferometry, J. Glaciol., 45, 532-546.

Favier, L., G. Durand, S. Cornford, G. Gudmundsson, O. Gagliardini, F. Gillet-Chaulet, T. Zwinger, A. Payne, and A. Le Brocq (2014), Retreat of pine island glacier controlled by marine ice-sheet instability, Nat. Clim. Change, 4, 117-121.

Fowler, A. (1987), A theory of glacial surges, J. Geophys. Res., 92(B9), 9111-9120, doi:10.1029/JB092iB09p09111.

Fowler, A., and E. Schiavi (1998), A theory of ice-sheet surges, J. Glaciol., 44(146), 104-118. 
Fowler, A., T. Murray, and F. Ng (2001), Thermally controlled glacier surging, J. Glaciol., 47(159), 527-538.

Fried, M., C. Hulbe, and M. Fahnestock (2014), Grounding-line dynamics and margin lakes, Ann. Glaciol., 55(56), 87-96.

Goldberg, D., D. Holland, and C. Schoof (2009), Grounding line movement and ice shelf buttressing in marine ice sheets, J. Geophys. Res., 114, F04026, doi:10.1029/2008JF001227.

Graham, A., R. Larter, K. Gohl, J. Dowdeswell, C. Hillenbrand, J. A. Smith, J. Evans, G. Kuhn, and T. Deen (2010), Flow and retreat of the late quaternary pine island-thwaites palaeo-ice stream, West Antarctica, J. Geophys. Res., 115, F03025, doi:10.1029/2009JF001482.

Greenberg, J., and W. Shyong (1990), Surging glacial flows, IMA J. Appl. Math., 45(3), 195-223.

Hindmarsh, R., and E. Le Meur (2001), Dynamical processes involved in the retreat of marine ice sheets, J. Glaciol., 47(157), 271-282.

Hollin, J. T (1962), On the glacial history of antarctica, J. Glaciol., 4, 172-195.

Horgan, H., and S. Anandakrishnan (2006), Static grounding lines and dynamic ice streams: Evdience from the Siple Coast, West Antarctica, Geophys. Res. Lett., 33, L18502, doi:10.1029/2006GL027091.

Hulbe, C., and M. Fahnestock (2004), West Antarctic ice-stream discharge variability: Mechanism, controls and pattern of grounding-line retreat, J. Glaciol., 50(171), 471-484, doi:10.3189/172756504781829738.

Hulbe, C., and M. Fahnestock (2007), Century-scale discharge stagnation and reactivation of the Ross ice streams, West Antarctica, J. Geophys. Res., 112, F03S27, doi:10.1029/2006JF000603.

Hulbe, C., and I. Whillans (1997), Weak bands within Ice Stream B, West Antarctica, J. Glaciol., 43(145), 377-386.

Jamieson, S., A. Vieli, S. Livingstone, C. Cofaigh, C. Stokes, C. Hillenbrand, and J. Dowdeswell (2012), Ice-stream stability on a reverse bed slope, Nat. Geosci., 5(11), 799-802.

Joughin, I., and S. Tulaczyk (2002), Positive mass balance of the Ross ice stream, West Antarctica, Science, 295, 476-452.

Joughin, I., et al. (2005), Continued deceleration of Whillans Ice Stream, West Antarctica, Geophys. Res. Lett., 32, L22501, doi:10.1029/2005GL024319.

Katz, R., and M. Worster (2010), Stability of ice-sheet grounding lines, Proc. R. Soc. A, 466, 1597-1620, doi:10.1098/rspa.2009.0434. Kyrke-Smith, T., R. Katz, and A. Fowler (2013), Subglacial hydrology and the formation of ice streams, Proc. R. Soc. A, 470, 20,130,494. Livingstone, S., C. Cofaigh, C. Stokes, C. Hillenbrand, A. Vieli, and S. Jamieson (2012), Antarctic palaeo-ice streams, Earth Sci. Rev., 111, $90-128$.

Luthra, T., R. Alley, and S. Anadakrishnan (2013), Seismic imaging of former grounding lines beneath Whillans Ice Stream, West Antarctica, Abstract C33B-0719 paper presented at 2013 Fall Meeting, AGU, San Francisco, Calif.

MacAyeal, D. (1993), Binge/purge oscillations of the laurentide ice sheet as a cause of the north atlantic heinrich events, Paleoceanography, 8(6), 775-784.

Mosola, A. B., and J. B. Anderson (2006), Expansion and rapid retreat of the west antarctic ice sheet in eastern ross sea: Possible consequence of over-extended ice streams?, Quat. Sci. Rev., 25(17-18), 2177-2196, doi:10.1016/j.quascirev.2005.12.013.

Nick, F., A. Vieli, I. Howat, and I. Joughin (2009), Large-scale changes in Greenland outlet glacier dynamics triggered at the terminus, Nat. Geosci, 2(2), 110-114.

O'Brien, P., L. D. Santis, P. Harris, E. Domack, and P. Quilty (1999), Ice shelf grounding zone features of western prydz bay, antarctica: Sedimentary processes from seismic and sidescan images, Antarct. Sci., 11, 78-91, doi:10.1017/S0954102099000115.

Oerlemans, J. (1982), Glacial cycles and ice-sheet modelling, Clim. Change, 4(4), 353-374.

Papa, B., L. Mysek, and Z. Wang (2006), Intermittent ice sheet discharge events in northeastern North America during the last glacial period, Clim. Dyn., 26, 201-206.

Payne, A. (1995), Limit cycles in the basal thermal regime of ice sheets, J. Geophys. Res., 100(B3), 4249-4263.

Payne, A. J., A. Vieli, A. P. Shepherd, D. J. Wingham, and E. Rignot (2004), Recent dramatic thinning of largest west antarctic ice stream triggered by oceans, Geophys. Res. Lett., 31, L23401, doi:10.1029/2004GL021284.

Pollard, D., and R. DeConto (2009), Modelling West Antarctic ice sheet growth and collapse through the past five million years, Nature, 458(7236), 329-332.

Price, S., H. Conway, E. Waddington, and R. Bindschadler (2008), Model investigations of inland propagation of fast-flowing outlet glaciers and ice streams, J. Glaciol., 54(184), 49-60.

Rempel, A. (2008), A theory for ice-till interactions and sediment entrainment beneath glaciers, J. Geophys. Res., 113, F01009, doi:10.1029/2007JF000870.

Retzlaff, R., and C. Bentley (1993), Timing of stagnation of Ice Stream C, West Antarctica, from short pulse radar studies of buried surface crevasses, J. Glaciol., 39(133), 553-561.

Rignot, E., J. Bamber, M. van den Broeke, C. Davis, Y. Li, W. van de Berg, and E. van Meijgaard (2008), Recent Antarctic ice mass loss from radar interferometry and regional climate modeling, Nat. Geosci., 1(2), 106-110, doi:10.1038/ngeo102.

Rignot, E., J. Mouginot, and B. Scheuchl (2011), Antarctic grounding line mapping from differential satellite radar interferometry, Geophys. Res. Lett., 38, L10504, doi:10.1029/2011GL047109.

Robel, A., E. DeGiuli, C. Schoof, and E. Tziperman (2013), Dynamics of ice stream temporal variability: Modes, scales and hysteresis, J. Geophys. Res. Earth Surf., 118, 925-936, doi:10.1002/jgrf.20072.

Robin, G. D. Q. (1955), Ice movement and temperature distribution in glaciers and ice sheets, J. Glaciol., 2(18), 523-532.

Schoof, C. (2004), Bed topography and surges in ice streams, Geophys. Res. Lett., 31, L06401, doi:10.1029/2003GL018807.

Schoof, C. (2006), A variational approach to ice stream flow, J. Fluid Mech., 556, 227-251, doi:10.1017/S0022112006009591.

Schoof, C. (2007a), Marine ice-sheet dynamics. Part 1. The case of rapid sliding, J. Fluid Mech., 573, 27-55,

doi:10.1017/S0022112006003570.

Schoof, C. (2007b), Ice sheet grounding line dynamics: Steady states, stability, and hysteresis, J. Geophys. Res., 112, F03S28, doi:10.1029/2006JF000664.

Schoof, C. (2012), Thermally driven migration of ice-stream shear margins, J. Fluid Mech., 712, 552-578, doi:10.1017/jfm.2012.438.

Shabtaie, S., and C. Bentley (1987), West Antarctic ice stream draining into the Ross Ice Shelf: Configuration and mass balance, J. Geophys. Res., 92(B2), 1311-1336.

Shumskiy, P., and M. Krass (1976), Mathematical models of ice shelves, J. Glaciol., 17(77), 419-432.

Thomas, R., S. Stephenson, R. Bindschadler, S. Shabtaie, and C. Bentley (1988), Thinning and grounding-line retreat on Ross Ice Shelf Antractica, Ann. Glaciol., 11, 165-172.

Tulaczyk, S., W. Kamb, and H. Engelhardt (2000a), Basal mechanics of Ice Stream B, West Antarctica 1. Till mechanics, J. Geophys. Res., 105(B1), 463-481, doi:10.1029/1999JB900329.

Tulaczyk, S., W. Kamb, and H. Engelhardt (2000b), Basal mechanics of Ice Stream B, West Antarctica 2. Undrained plastic bed model, J. Geophys. Res., 105(B1), 483-494, doi:10.1029/1999JB900328. 
van der Wel, N., P. Christoffersen, and M. Bougamont (2013), The influence of subglacial hydrology on the flow of Kamb Ice Stream, West Antarctica, J. Geophys. Res. Earth Surf., 118, 97-110, doi:10.1029/2012JF002570.

Vieli, A., and A. Payne (2005), Assessing the ability of numerical ice sheet models to simulate grounding line migration, J. Geophys. Res., 110, F01003, doi:10.1029/2004JF000202.

Weertman, J. (1974), Stability of the junction of an ice sheet and an ice shelf, J. Glaciol., 13, 3-11. 